\title{
Effects of cutting and sowing seeds of native species on giant ragweed invasion and plant diversity in a field experiment
}

\author{
Chaeho Byun ${ }^{1,2}, \mathrm{Ho} \mathrm{Choi}^{3}$ and Hojeong Kang ${ }^{2 *}$
}

\begin{abstract}
Background: Ambrosia trifida is a highly invasive annual plant, but effective control methods have not been proposed. Among various eradication methods, cutting is a simple measure to control invasive plants, and sowing seeds of native plants may effectively increase biotic resistance to invasion. In this study, we conducted a field experiment with two treatments: cutting and sowing seeds of six native or naturalized plants.

Results: We found a significantly lower A. trifida abundance after cutting than in the control (77\% decrease). Sowing seeds of native species did not provide any additional benefit for the control of $A$. trifida, but increased the importance values and diversity of other native vegetation. The abundance of $A$. trifida was negatively correlated with that of other plant taxa based on plant cover, biomass, and density. However, biotic resistance of sown plants was not effective to control invasion because $A$. trifida was so competitive.
\end{abstract}

Conclusions: We concluded that cutting is an effective measure to control Ambrosia trifida while sowing seeds of native plants can increase native plant diversity.

Keywords: Ambrosia trifida, Biotic resistance, Eradication methods, Invasive plant management, Plant restoration

\section{Introduction}

Ambrosia trifida, commonly called giant ragweed, is a troublesome weed species worldwide, which is native to North America (Bassett and Crompton 1982). It is a noxious weed for crop plants (Baysinger and Sims 1991; Harrison et al. 2001; Brandes and Nitzsche 2006) and is thus listed as one of the most ecologically destructive weeds (Kong et al. 2007). In addition, it decreases plant diversity by dominating communities, accounting for most of the plant biomass (Abul-Fatih and Bazzaz 1979; Washitani 2001). It is also harmful to humans, as it produces pollen with the potential to cause allergic reactions (Gadermaier et al. 2004). It is considered as a very noxious invasive plant in South Korea.

\footnotetext{
* Correspondence: hj_kang@yonsei.ac.kr

${ }^{2}$ School of Civil and Environmental Engineering, Yonsei University, Yonsei-ro 50, Seodaemun-gu, Seoul 03722, South Korea

Full list of author information is available at the end of the article
}

Conventionally, invasive plants are controlled by cutting and herbicide application (Kettenring and Adams 2011). Controlling A. trifida is extremely difficult owing to its strong resistance to herbicides (Vink et al. 2012). The repeated application of herbicides may be required to control such invasive plants (Derr 2008; Kaur et al. 2014), which is costly and may lead to other environmental problems, such as bioaccumulation (Wolfaardt et al. 1995). Cutting has not been evaluated as a control method for A. trifida. A closely related species, the common ragweed Ambrosia artemisiifolia, is well controlled by cutting (Simard and Benoit 2011; Milakovic et al. 2014). However, the natural recovery of native plants is not guaranteed by the eradication of invasive plants alone (Harms and Hiebert 2006; Reid et al. 2009).

Enhancing biotic resistance to invasion by sowing seeds of native species is a promising way to decrease the community invasibility (Kettenring and Adams 2011; Byun et al. 2013; Byun et al. 2015; Byun and Lee 2017).

(c) The Author(s). 2020 Open Access This article is licensed under a Creative Commons Attribution 4.0 International License, which permits use, sharing, adaptation, distribution and reproduction in any medium or format, as long as you give appropriate credit to the original author(s) and the source, provide a link to the Creative Commons licence, and indicate if changes were made. The images or other third party material in this article are included in the article's Creative Commons licence, unless indicated otherwise in a credit line to the material. If material is not included in the article's Creative Commons licence and your intended use is not permitted by statutory regulation or exceeds the permitted use, you will need to obtain permission directly from the copyright holder. To view a copy of this licence, visit http://creativecommons.org/licenses/by/4.0/. 
Sowing of native seeds to control $A$. artemisiifolia (not A. trifida) has been tested successfully (Gentili et al. 2015; Gentili et al. 2017; Skalova et al. 2019). However, A. trifida did not respond well to biotic resistance to invasion in our previous study (Byun and Lee 2018). The species is highly competitive against other plants as a result of its early germination, rapid vertical growth, and the formation of a tall and dense canopy (Abul-Fatih et al. 1979). In our previous study, we concluded that the restoration of native species to control A. trifida may require very dense plant cover by sowing seeds at an extremely high density (Byun and Lee 2018). Furthermore, the initial removal of $A$. trifida (by cutting or herbicide application) may be required prior to the restoration of native species to ensure success.

Accumulating evidence indicates that seed density regulates biotic resistance to invasion (Reinhardt Adams and Galatowitsch 2008; Nemec et al. 2013; Byun et al. 2015; Adomako et al. 2019). Sowing a high number of seeds of native species can create a dense and complex canopy that blocks sunlight and efficiently uptakes soil resources (Lindig-Cisneros and Zedler 2002b; LindigCisneros and Zedler 2002a). Recent evidence suggests that seed density may be more important than limiting similarity (Yannelli et al. 2018). Density is also related to the cost of restoration, considering the need to purchase seeds. Accordingly, precise analyses of the number of seeds of native species required to control invasive plants, such as $A$. trifida, are needed, beyond analyses of the type of species required (limiting similarity) or the number of species required (diversity effect).

In this study, we evaluated the effect of the seed density of native species on biotic resistance to invasion by A. trifida in addition to conventional control measures, such as cutting. We hypothesized that (1) cutting will reduce the abundance of $A$. trifida compared with that in the control, (2) the combination of sowing native seeds and cutting will further reduce the abundance of $A$. trifida, and (3) increasing the density of seeds sown will reduce invasion success, but there will be a threshold effect (i.e., seed density will not increase biotic resistance after the density exceeds a certain level).

\section{Materials and methods}

\section{Species selection and functional classification}

Six species (Zea mays, Secale cereale, Trifolium repens, Pennisetum alopecuroides, Lespedeza juncea, and Lespedeza bicolor) were selected based on a previous study (Byun and Lee 2018) in addition to the availability of seed and ensuring high functional diversity. In a previous study about a pot experiment, the six species showed the strongest biotic resistance to invasion by $A$. trifida, in each function group (annual, perennial herbaceous, and perennial woody plant). Two species (Z. mays and $S$. cereale) were annual plants, two species (T. repens and $P$. alopecuroides) were perennial herbaceous plants, and two species were perennial woody plants (L. juncea var. sericea and $L$. bicolor). Although we want to test and restore all native plants initially, many native species had weaker competitiveness than $A$. trifida, and they showed very weak biotic resistance to invasion by $A$. trifida in a previous pot study (Byun and Lee 2018). Particularly, some non-native species (e.g., Zea mays or Secale cereal) showed strong biotic resistance (30 40\% reduction for the abundance of $A$. trifida) in a previous pot study (Byun and Lee 2018). Therefore, we had to use Zea mays, Secale cereal, and Trifolium repens even though they are nonnative or crop species because they are naturalized species in the study region and because of their cheap price of seeds and easy accessibility to market for restoration.

\section{Seed preparation}

Most seeds of native plants were purchased from seed suppliers. Seed viability was standardized by applying an identical number of viable seeds per species to experimental units. To determine pure live seeds, a germination test was conducted. All seeds were cold-stratified (6 months) at $3^{\circ} \mathrm{C}$ before the germination test, following standard methods (Lindig-Cisneros and Zedler 2001). Before the experiment, 100 seeds per species were placed in each of three Petri dishes with filter paper (Whatman ${ }^{\circ}$ No. 1) moistened with $6 \mathrm{~mL}$ of distilled water under fluorescent light.

\section{Experimental design}

Experimental plots were installed in Jung-ri 507, Gwanin-myeon, Pocheon City, Gyeonggi Province, South Korea (latitude: $38^{\circ} 5^{\prime} 11.08^{\prime \prime} \mathrm{N}$, longitude: $127^{\circ} 12^{\prime}$ 29.76" E) in May 2019 (Fig. 1). The site was an abandoned paddy field and was located in the floodplain of Hantan River, dominated by A. trifida (>90\% cover).

Plots measuring $1 \times 1 \mathrm{~m}^{2}$ were prepared for seven treatments including a control. Table 1 shows the detailed experimental design of this study. In control plots, nothing was applied. For the cutting treatment, all plant species (including $A$. trifida) were cut by hand and left. Cutting was occurred at the lowest stem part of all plant (right above top of the belowground part) in early May. In the five seed treatments, all plant species (including A. trifida) were cut and seeds of native species were sown. Five seed densities of native species were evaluated (density 1, 300 viable seeds; density 2, 600 viable seeds; density 3, 1200 viable seeds; density 4, 2400 viable seeds; and density 5, 4800 viable seeds of six species per plot). The total number of seeds was divided by six to calculate the number of seeds of each species. All treatments were applied in a randomized complete block design, with four replicates per treatment (four blocks). 


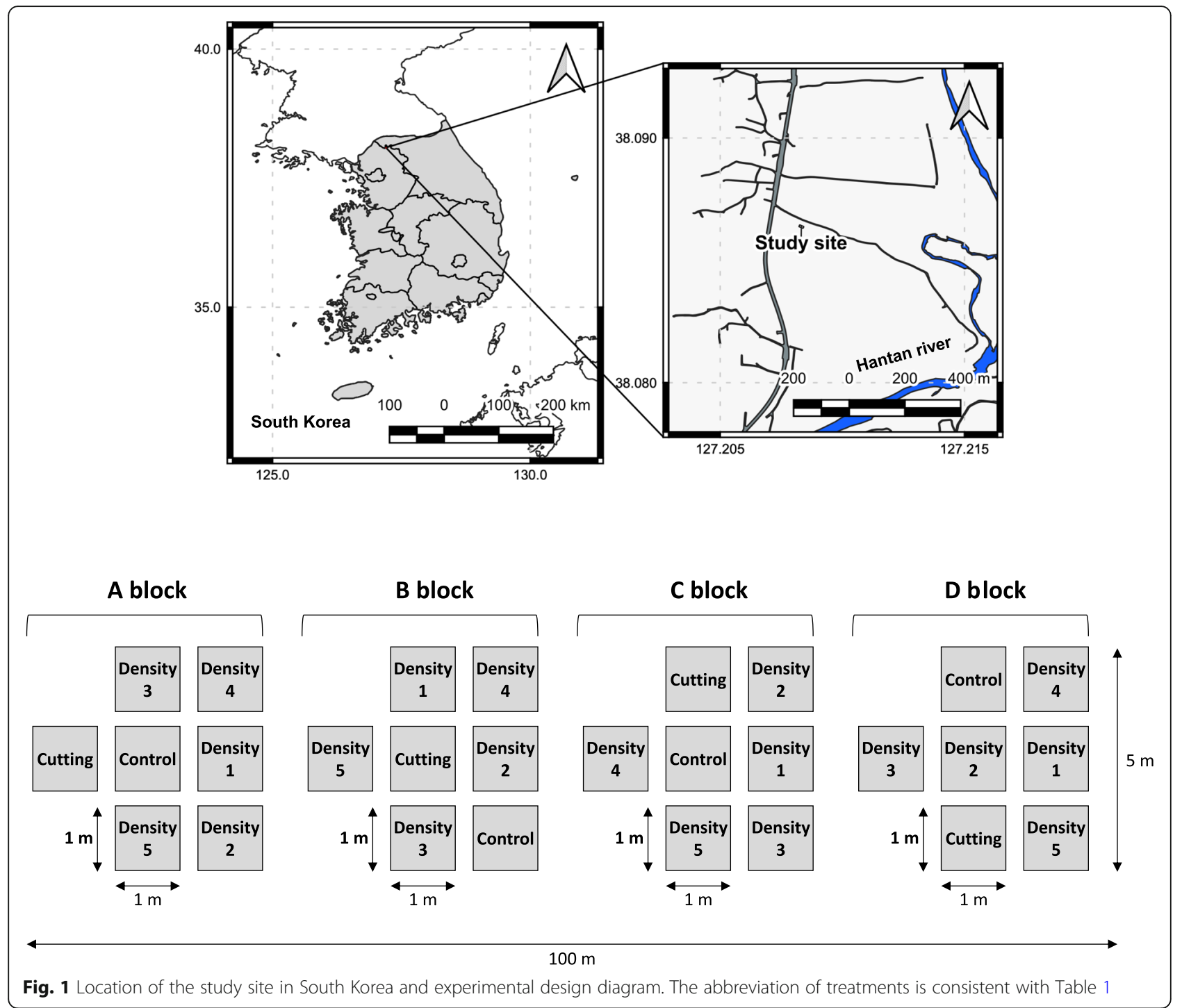

Table 1 Experimental design of control, cutting, and species' composition for seeding treatments

\begin{tabular}{|c|c|c|c|c|c|c|c|c|c|}
\hline & & & \multicolumn{7}{|c|}{ Treatments } \\
\hline & & & Control & Cutting & $\begin{array}{l}\text { Density } \\
1\end{array}$ & $\begin{array}{l}\text { Density } \\
2\end{array}$ & $\begin{array}{l}\text { Density } \\
3\end{array}$ & $\begin{array}{l}\text { Density } \\
4\end{array}$ & $\begin{array}{l}\text { Density } \\
5\end{array}$ \\
\hline \multicolumn{3}{|l|}{ Cutting all plant species } & - & $\circ$ & $\circ$ & $\circ$ & $\circ$ & $\circ$ & $\circ$ \\
\hline \multirow{6}{*}{$\begin{array}{l}\text { Sowing seeds density (viable } \\
\text { seeds per plot) }\end{array}$} & \multirow[t]{2}{*}{ Annual plant } & Zea mays & - & - & 50 & 100 & 200 & 400 & 800 \\
\hline & & Secale cereale & - & - & 50 & 100 & 200 & 400 & 800 \\
\hline & \multirow{2}{*}{$\begin{array}{l}\text { Perennial } \\
\text { herbaceous plant }\end{array}$} & Trifolium repens & - & - & 50 & 100 & 200 & 400 & 800 \\
\hline & & $\begin{array}{l}\text { Pennisetum } \\
\text { alopecuroides }\end{array}$ & - & - & 50 & 100 & 200 & 400 & 800 \\
\hline & \multirow{2}{*}{$\begin{array}{l}\text { Perennial woody } \\
\text { plant }\end{array}$} & Lespedeza juncea & - & - & 50 & 100 & 200 & 400 & 800 \\
\hline & & Lespedeza bicolor & - & - & 50 & 100 & 200 & 400 & 800 \\
\hline
\end{tabular}




\section{Data measurement and analyses}

When the experiment was set up in early May 2019 (initial of growing season), plant height and cover of $A$. trifida were measured in all plots. Before the experiment, plant cover and plant height of $A$. trifida did not differ significantly among treatments and controls $(P=0.167$ and $P=0.220)$. The average plant cover of $A$. trifida was 93.4\% $(n=28)$, and height was $44.82 \mathrm{~cm}(n=28)$. We started the experiment in early May to maximize the effect of eradication methods on $A$. trifida. In late October 2019 (we measured the experiment this time because it is the end of the growing season), the number of shoots, aboveground biomass, plant height, and plant cover of A. trifida in each treatment and control plot was measured to calculate the primary response variables (see below). Additionally, the number of shoots, plant cover, plant height, and aboveground biomass of all native plants was measured to evaluate their correlations with the response variables. For the number of shoots, we counted all shoots of each species in each plot manually. For the plant cover, the percentage of each species was estimated using reference frames representing $50 \%$ and $25 \%$ of the total plot area. For aboveground biomass, the aboveground portion of plants was harvested in late October and weighed after drying at $80^{\circ} \mathrm{C}$ for $48 \mathrm{~h}$.

The main response variable was the abundance of $A$. trifida based on plant cover and biomass. Additional response values included the abundance of other vegetation (all other plants except for A. trifida) and the Shannon-Wiener diversity index $\left(\mathrm{H}^{\prime}\right)$ of all plants. Importance values were calculated by summing the relative plant cover (\%) and the relative shoot density (\%).

ANOVA was used to evaluate the effects of cutting and seed density. A generalized linear mixed model (REML; $F$ test) was used to account for the random block design (Bolker et al. 2009). The normality of residuals and homoscedasticity were evaluated, and the response variables were transformed when necessary. When treatment effects were detected, Tukey's HSD multiple comparison test was used to compare means of treatments.

ANOVA and correlation analyses were conducted using JMP (SAS Institute Inc., Cary, NC, USA).

\section{Results}

The abundance (in terms of biomass and plant cover) of A. trifida differed significantly among treatments. Likewise, the biomass of $A$. trifida differed significantly among treatments $\left(F_{6,18}=10.24 ; P<0.001\right)$. A trifida biomass was significantly lower in the cutting and seed density treatments than in control, but no differences among seed density treatments were detected (Fig. 2). For A. trifida, plant cover differed significantly among treatments $\left(F_{6,18}=6.29 ; P=0.001\right)$. A. trifida cover was significantly lower in cutting and seed density treatments than in the control, but there were no differences among seed density treatments (Fig. 2).

We detected 25 species (other than A. trifida) in the experimental plots (Table S1). Among them, 16 species were annual or biennial plants, 8 were perennial herbaceous plants, and 1 was a perennial woody plant. The dominant species (excluding A. trifida) were Setaria viridis (importance value $=20.9 \%)$, Bidens frondosa $(14.3 \%)$, and Panicum bisulcatum (13.0\%).

The abundance and diversity of other vegetation (the sum of all native plants other than A. trifida) were significantly different among treatments. Importance values for other vegetation were significantly different among treatments (log-transformed, $F_{6,18}=5.99 ; P=0.001$ ). Importance values for other vegetation in seed density treatments were significantly greater than those of the control, but importance values for other vegetation in the cutting treatment were not significantly greater than those in the control (Fig. 3). The diversity index $\mathrm{H}^{\prime}$ of other vegetation differed significantly among treatments $\left(F_{6,18}=4.48 ; P=0.006\right)$. The diversity index $\mathrm{H}^{\prime}$ of other vegetation for some seed density treatments was significantly greater than that of the control, but there was no difference between the cutting treatment and the control (Fig. 3).

The abundance of $A$. trifida was negatively correlated with the abundance of other vegetation in terms of plant cover, density (number of shoots in a plot), and biomass (Fig. 4). A. trifida plant cover was significantly and negatively correlated with the plant cover of other vegetation (Pearson correlation coefficient, $r=-0.583 ; P=0.001$ ). The number of shoots of $A$. trifida was significantly and negatively correlated with the number of shoots of other vegetation $(r=-0.673 ; P<0.001)$. A. trifida biomass was negatively correlated with the biomass of other vegetation $(r=-0.314 ; P=0.103)$.

\section{Discussion}

Our results suggest that cutting is an effective measure to control A. trifida invasion, and sowing seeds of native plants does not provide additional control benefits (Fig. 2). Instead, the combination of sowing native seeds and cutting improved the abundance and diversity of other vegetation, while cutting alone did not have such an effect (Fig. 3). We also found a negative relationship between other vegetation and A. trifida in terms of plant cover, biomass, and density (Fig. 4).

This study is the analysis of cutting as a control measure against $A$. trifida. At seedling stages, (e.g., May), this study indicated that cutting the bottom of stems of $A$. trifida by hand is preferred and effective control measure against $A$. trifida invasion. After the seedling stage, it was observed during the experiment that even if the 


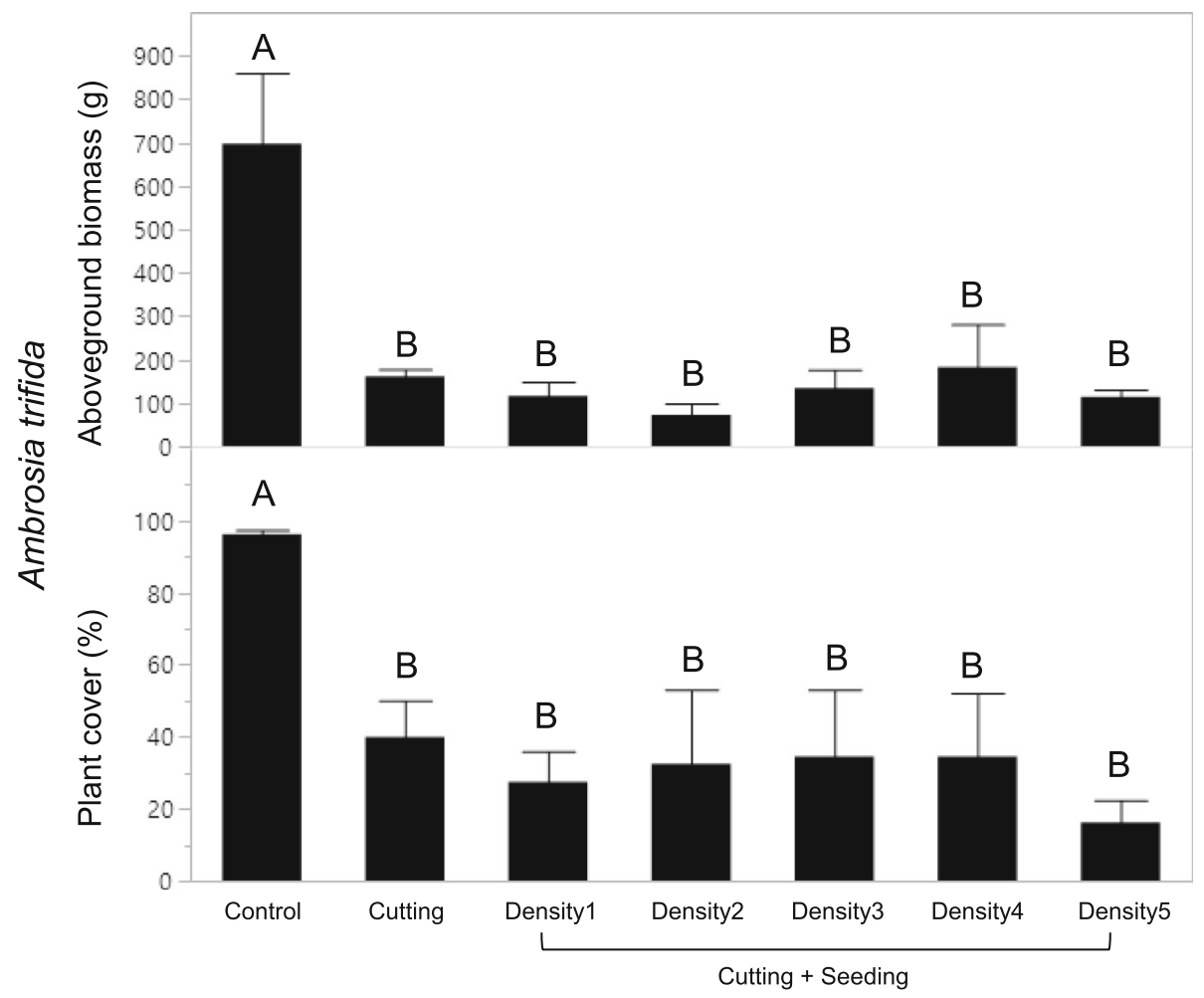

Fig. 2 Abundance of Ambrosia trifida based on biomass and plant cover in late October. Values are means \pm SE. In the cut treatment, all plants were subjected to cutting in early May. In density 1, all plants were cut and seeds of six species were sown at 300 viable seeds per plot. In addition, density 2 included 600 viable seeds, density 3 included 1200 viable seeds, density 4 included 2400 viable seeds, and density 5 included 4800 viable seeds of six species per plot

main stem was cut, A. trifida can bloom and fruit by giving out a new stem. Therefore, cutting at seedling stage is critical to control $A$. trifida. Although we cut plants by hand, we recommend cutting by a mower for the larger area to save managemental cost. Previous studies of related species have reported similar results, supporting the effectiveness of the approach. For example, mowing significantly affects $A$. artemisiifolia (common ragweed) reproduction, as the species reacts to cutting by producing new shoots (Simard and Benoit 2011; Milakovic et al. 2014), and Weber (2017) recommended mowing twice a year for the control of $A$. artemisiifolia.

Cutting and sowing seeds of other six plants increased the diversity index of restored plant communities (except A. trifida). Although our results indicated the diversity index in cutting or densities 2 , 3 , and 4 was not significantly different from that in control (Fig. 3), the averaged means of diversity index were higher in the treatments than in control. Because the experiment was conducted in a field situation, unexpected and uncontrolled environmental factors can influence the results. If we increase replicates of treatments, it may lead to significant difference in the results.
The lack of the effect of native vegetation on $A$. trifida invasion has several potential explanations. First, invasion and regrowth of $A$. trifida were so competitive that other vegetation could not suppress them easily. It is also possible that sown seeds did not establish well because of field-specific situations. In our previous microcosm experiment, seeds of most species established well in pots with fertile soil. However, seed germination and establishment in the field require speciesspecific conditions, and further consideration of environmental properties may be necessary. A. trifida is usually found in the floodplain, $60-79 \mathrm{~cm}$ above the water table, and shares a niche with riverine species, such as Phalaris arundinacea (another invasive plant), Impatiens spp., and Symphyotrichum ontarionis (Menges and Waller 1983). Considering these ecological factors, it is necessary to carefully select species that can easily adapt to the field environment where A. trifida occurs. For instance, in the case of corn (Zea mays), crops significantly reduce their ability to regenerate in their natural state. Because of this characteristic, Z. mays did not establish well enough to control $A$. trifida in our experiment. Although it was the best candidate for the invasion-resistant plant species to control $A$. trifida in a 


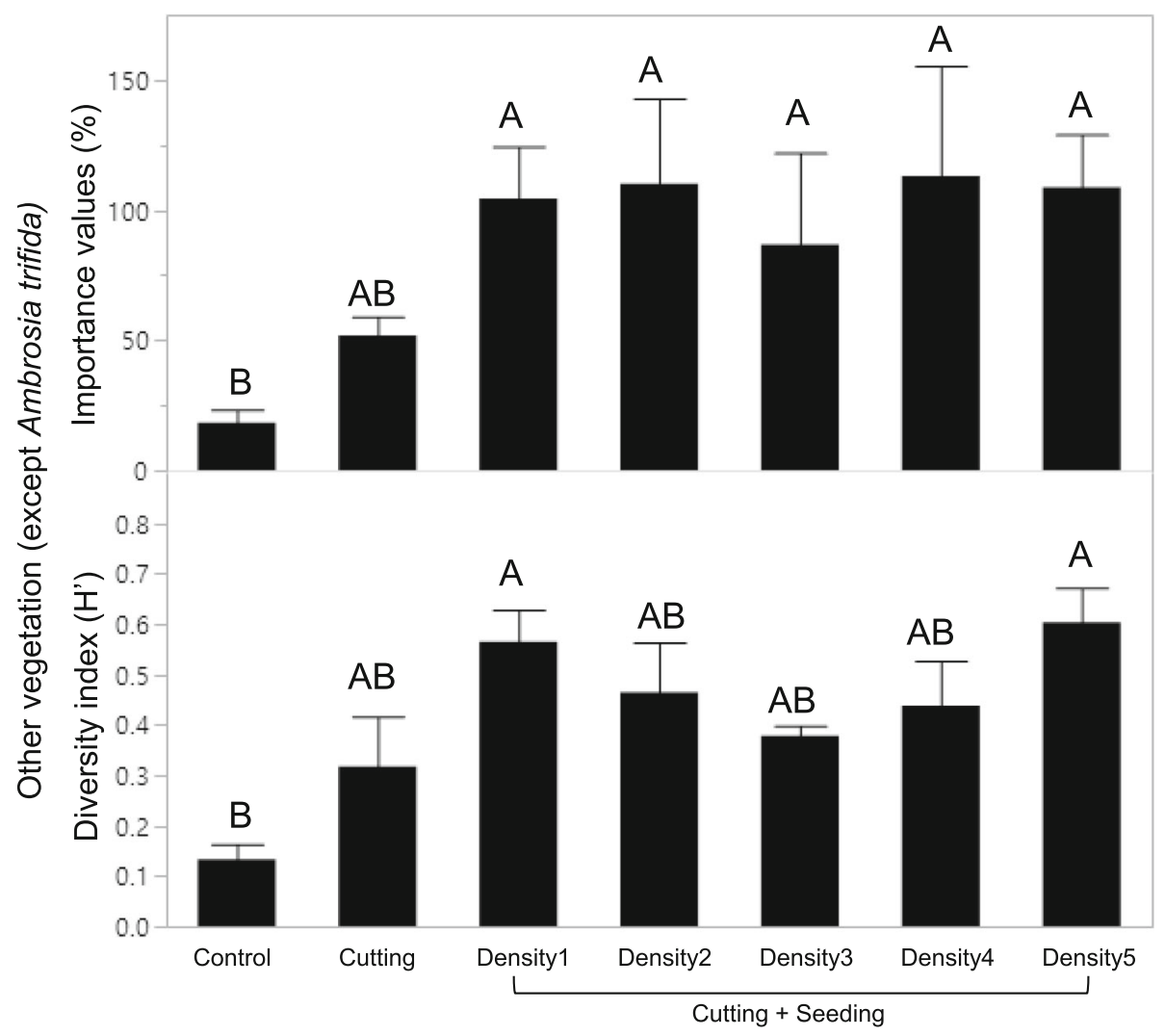

Fig. 3 Abundance and diversity of other vegetation (sum of all plants except A. trifida) for the treatments in late October. Values are means \pm SE. For the cut treatment, all plants were cut in early May. In density 1, all plants were cut and seeds of six species were sown at 300 viable seeds per plot. In addition, density 2 included 600 viable seeds, density 3 included 1200 viable seeds, density 4 included 2400 viable seeds, and density 5 included 4800 viable seeds of six species per plot

previous experiment (Byun and Lee 2018), it may not be applicable to a field situation. In addition, advanced restoration techniques to facilitate establishment after sowing may be required. For example, the immediate application of water on sown seeds may be important for germination. Mixing seeds with special medium types, such as peat moss, can be considered (Carley and Watson 1968). Coating seeds with nutrients is also recommended to facilitate establishment in the field (Scott 1989).

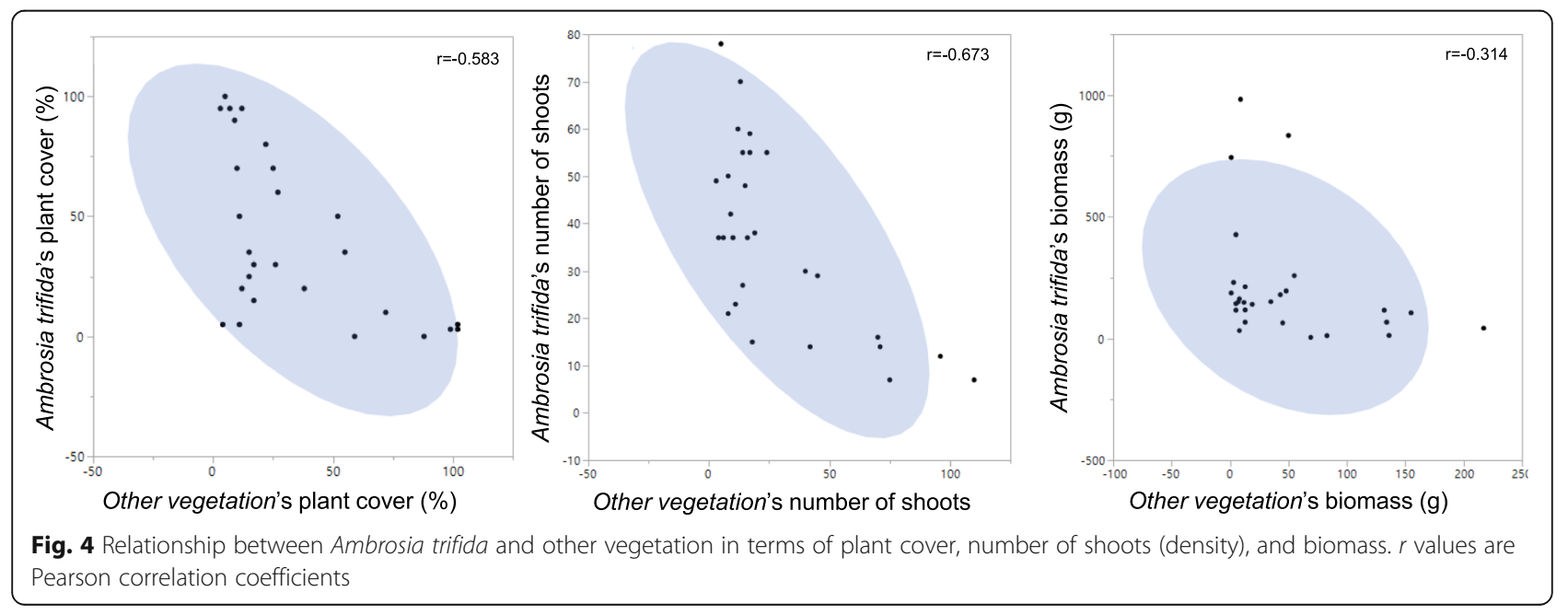


Another possible cause of unsuccessful establishment would be the timing of seed sowing. We sowed seeds right after cutting the $A$. trifida population in early May. It is possible that the sown seeds of most species could be outcompeted by A. trifida or previously established vegetation. We cut all plant species together with $A$. trifida, but some of individuals might regrow easily from underground parts, conferring a competitive advantage. We recommend sowing seeds earlier than early May, possibly early March to maximize biotic resistance to invasion. Then, another associated problem is that it may be very difficult to identify population of $A$. trifida in early March, so we recommend cutting $A$. trifida a year before sowing seeds of native plants.

Only one study has reported the use of native plant restoration to suppress A. trifida invasion (Lee et al. 2010). The introduction of willow (Salix sp.) significantly suppressed the growth of $A$. trifida after 3 years in a riparian site. In addition, the introduction of willow increased plant species diversity. However, it is difficult to compare these results with those of the current study, as saplings were used instead of seeds.

Another important finding of this study is that increasing the seed density did not increase biotic resistance to invasion, as treatment results did not differ significantly with respect to seed density (Figs. 2 and 3). In previous studies, invasive plants have exhibited mixed responses to native seed density. For example, sowing seeds of native wet meadow species can successfully control the invasion of Phalaris arundinacea and lead to a transition to a new native plant community (Reinhardt Adams and Galatowitsch 2008). Seed density is a significant factor for the control of Solidago canadensis (Adomako et al. 2019). Increasing seed density clearly has a significant inhibitory effect against the establishment of seedlings of Phragmites australis (Byun et al. 2015) and Sicyos angulatus (Byun et al. 2020). However, seedling density does not influence invasion resistance in experimental tallgrass prairie plots (Nemec et al. 2013).

In conclusion, our results showed that biotic resistance of native species was not an effective measure to control A. trifida and should be coupled with extensive eradication methods. However, sowing seeds of native plants may improve the abundance and diversity of vegetation other than $A$. trifida. Restoration goals can be broad and usually include increasing biodiversity in addition to the control of invasive plants. When eradication methods are applied for invasive plant management, the restoration of native vegetation by sowing seeds of native plants is recommended to improve plant diversity.

\section{Supplementary Information}

Supplementary information accompanies this paper at https://doi.org/10. 1186/s41610-020-00173-8.

Additional file 1: Table S1. List of species found in the experimental plots.

\section{Acknowledgements}

We thank Hyona Kim, Yunjae Kim, and Chaeyoung Byun for assistance with the fieldwork. We also thank Minwoo Oh for drawing the study site map in QGIS. This work was supported by the National Research Foundation of Korea (NRF) grant funded by the Korean government (MSIT)

(2018R1C1B6005351).

\section{Authors' contributions}

$\mathrm{CB}$ and $\mathrm{HK}$ conceived the study. CB designed the experiments, analyzed the data, and wrote the manuscript. $\mathrm{CB}$ and $\mathrm{HC}$ performed the experiments and obtained the data. All authors revised the manuscript and approved the final version.

\section{Funding}

This work was supported by the National Research Foundation of Korea (NRF) grant funded by the Korean government (MSIT) (2018R1C1B6005351).

Availability of data and materials

Please contact author for data request.

Ethics approval and consent to participate

Not applicable.

Consent for publication

Not applicable.

\section{Competing interests}

The authors declare that they have no competing interests.

\section{Author details}

'Department of Biological Sciences and Biotechnology, Andong National University, Andong 36729, South Korea. ${ }^{2}$ School of Civil and Environmental Engineering, Yonsei University, Yonsei-ro 50, Seodaemun-gu, Seoul 03722, South Korea. ${ }^{3}$ Department of Biology Education, Seoul National University, Seoul 08826, South Korea.

Received: 8 October 2020 Accepted: 12 November 2020

Published online: 25 November 2020

\section{References}

Abul-Fatih H, Bazzaz F. The biology of Ambrosia trifida L. I. Influence of species removal on the organization of the plant community. New Phytol. 1979;83(3):813-6.

Abul-Fatih HA, Bazzaz FA, Hunt R. The biology of Ambrosia Trifida L. II. Growth and biomass allocation. New Phytol. 1979;83:829-38.

Adomako MO, Ning L, Tang M, Du DL, van Kleunen M, Yu FH. Diversity- and density-mediated allelopathic effects of resident plant communities on invasion by an exotic plant. Plant Soil. 2019:440:581-92.

Bassett IJ, Crompton CW. The biology of Canadian weeds.: 55.: Ambrosia trifida L. Can J Plant Sci. 1982:62:1003-10.

Baysinger JA, Sims BD. Giant ragweed (Ambrosia trifida) interference in soybeans (Glycine max). Weed Sci. 1991;39:358-62.

Bolker BM, Brooks ME, Clark CJ, Geange SW, Poulsen JR, Stevens MH, White JS. Generalized linear mixed models: a practical guide for ecology and evolution. Trends Ecol. Evol. 2009:24:127-35.

Brandes D, Nitzsche J. Biology, introduction, dispersal, and distribution of common ragweed (Ambrosia artemisiifolia L.) with special regard to Germany. Nachrichtenblatt-deutschen Pflanzenschutzdienstes Braunschweig. 2006:58:286-91.

Byun C, de Blois S, Brisson J. Plant functional group identity and diversity determine biotic resistance to invasion by an exotic grass. J. Ecol. 2013;101: 128-39. 
Byun C, de Blois S, Brisson J. Interactions between abiotic constraint, propagule pressure, and biotic resistance regulate plant invasion. Oecologia. 2015;178: 285-96.

Byun C, Lee EJ. Ecological application of biotic resistance to control the invasion of an invasive plant, Ageratina altissima. Ecol Evol. 2017;7:2181-92.

Byun C, Lee EJ. Giant ragweed invasion is not well controlled by biotic resistance. J Plant Biol. 2018;61:301-8.

Byun C, Oh M, Lee EJ, Kang $\mathrm{H}$. Seed density is as important as limiting similarity, diversity effect, and propagule pressure in plant restoration to control invasion. Ecol. Eng. 2020;144:105712.

Carley HE, Watson R. Effect of various aqueous plant extracts upon seed germination. Botanical gazette. 1968;129:57-62.

Derr JF. Common reed (Phragmites Australis) response to mowing and herbicide application. Invas. Plant Sci. Manage. 2008;1:12-6.

Gadermaier G, Dedic A, Obermeyer G, Frank S, Himly M, Ferreira F. Biology of weed pollen allergens. Curr Allergy Asthma Rep. 2004;4:391-400.

Gentili R, Gilardelli F, Ciappetta S, Ghiani A, Citterio S. Inducing competition: intensive grassland seeding to control Ambrosia artemisiifolia. Weed Res. 2015;55:278-88.

Gentili R, Montagnani C, Gilardelli F, Guarino MF, Citterio S. Let native species take their course: Ambrosia artemisiifolia replacement during natural or "artificial" succession. Acta Oecol. 2017;82:32-40.

Harms RS, Hiebert RD. Vegetation response following invasive tamarisk (Tamarix spp.) removal and implications for riparian restoration. Restor. Ecol. 2006;14: 461-72.

Harrison SK, Regnier EE, Schmoll JT, Webb JE. Competition and fecundity of giant ragweed in corn. Weed Sci. 2001;49:224-9.

Kaur S, Sandell LD, Lindquist JL, Jhala AJ. Glyphosate-resistant giant ragweed (Ambrosia trifida) control in glufosinate-resistant soybean. Weed Technol. 2014;28:569-77.

Kettenring KM, Adams CR. Lessons learned from invasive plant control experiments: a systematic review and meta-analysis. J. Appl. Ecol. 2011;48: 970-9.

Kong $\mathrm{CH}$, Wang $\mathrm{P}, \mathrm{Xu} \mathrm{XH}$. Allelopathic interference of Ambrosia trifida with wheat (Triticum aestivum). Agr Ecosyst Environ. 2007;119:416-20.

Lee CS, Cho YC, Shin HC, Kim GS, Pi JH. Control of an invasive alien species, Ambrosia trifida with restoration by introducing willows as a typical riparian vegetation. J Ecol Environ. 2010;33:157-64.

Lindig-Cisneros R, Zedler J. Effect of light on seed germination in Phalaris arundinacea L. (reed canary grass). Plant Ecol. 2001;155:75-8.

Lindig-Cisneros R, Zedler JB. Phalaris arundinacea seedling establishment: effects of canopy complexity in fen, mesocosm, and restoration experiments. Can J Botany. 2002a;80:617-24.

Lindig-Cisneros R, Zedler JB. Relationships between canopy complexity and germination microsites for Phalaris arundinacea L. Oecologia. 2002b;133:159_ 67.

Menges ES, Waller DM. Plant strategies in relation to elevation and light in floodplain herbs. Am Naturalist. 1983;122:454-73.

Milakovic I, Fiedler K, Karrer G. Management of roadside populations of invasive Ambrosia artemisiifolia by mowing. Weed Res. 2014;54:256-64.

Nemec KT, Allen CR, Helzer CJ, Wedin DA. Influence of richness and seeding density on invasion resistance in experimental tallgrass prairie restorations. Ecol. Restor. 2013;31:168-85.

Reid AM, Morin L, Downey PO, French K, Virtue JG. Does invasive plant management aid the restoration of natural ecosystems? Biol. Conserv. 2009; 142:2342-9.

Reinhardt Adams C, Galatowitsch SM. The transition from invasive species control to native species promotion and its dependence on seed density thresholds. Appl Vegetation Sci. 2008;11:131-8.

Scott JM. Seed coatings and treatments and their effects on plant establishment. Pages 43-83 Advances in agronomy. Vol. 42. Netherlands: Elsevier; 1989. p. 43-83.

Simard M, Benoit DL. Effect of repetitive mowing on common ragweed (Ambrosia Artemissifolia L.) pollen and seed production. Ann. Agric. Environ. Med. 2011;18:55-62.

Skalova H, Wen-Yong G, Moravcova L, Pyšek P. Performance of Ambrosia artemisifolia and its potential competitors in an experimental temperature and salinity gradient and implications for management. Manage Biol Invasions. 2019;10:359.
Vink JP, Soltani N, Robinson DE, Tardif FJ, Lawton MB, Sikkema PH. Glyphosateresistant giant ragweed (Ambrosia trifida L.) control with preplant herbicides in soybean [Glycine max (L.) Merr.]. Can J Plant Sci. 2012;92:913-22.

Washitani I. Plant conservation ecology for management and restoration of riparian habitats of lowland Japan. Popul. Ecol. 2001;43:189-95.

Weber E. Invasive plant species of the world: a reference guide to environmental weeds. 2nd ed. Wallingford, UK: CABI Publishing; 2017.

Wolfaardt G, Lawrence J, Robarts R, Caldwell D. Bioaccumulation of the herbicide diclofop in extracellular polymers and its utilization by a biofilm community during starvation. Appl. Environ. Microbiol. 1995;61:152-8.

Yannelli FA, Karrer G, Hall R, Kollmann J, Heger T. Seed density is more effective than multi-trait limiting similarity in controlling grassland resistance against plant invasions in mesocosms. Appl Vegetation Sci. 2018;21:411-8.

\section{Publisher's Note}

Springer Nature remains neutral with regard to jurisdictional claims in published maps and institutional affiliations.
Ready to submit your research? Choose BMC and benefit from:

- fast, convenient online submission

- thorough peer review by experienced researchers in your field

- rapid publication on acceptance

- support for research data, including large and complex data types

- gold Open Access which fosters wider collaboration and increased citations

- maximum visibility for your research: over $100 \mathrm{M}$ website views per year

At $\mathrm{BMC}$, research is always in progress.

Learn more biomedcentral.com/submissions 